\title{
Evaluation of three different regional climate change scenarios for the application of a water balance model in a mesoscale catchment in Northeast Germany
}

\author{
M. Wegehenkel ${ }^{1}$, U. Heinrich ${ }^{2}$, H. Jochheim ${ }^{1}$, K. C. Kersebaum ${ }^{1}$, and B. Röber ${ }^{2}$ \\ ${ }^{1}$ Leibniz-Cetre for Agricultural Landscape Research (ZALF) e.V., Institute of Landscape Systems Analysis, \\ Müncheberg, Germany \\ ${ }^{2}$ Leibniz-Cetre for Agricultural Landscape Research (ZALF) e.V., Department of Landscape Information Systems, \\ Müncheberg, Germany
}

Received: 14 January 2010 - Revised: 21 May 2010 - Accepted: 30 May 2010 - Published: 27 August 2010

\begin{abstract}
Future climate changes might have some impacts on catchment hydrology. An assessment of such impacts on e.g. ground water recharge is required to derive adaptation strategies for future water resources management. The main objective of our study was an analysis of three different regional climate change scenarios for a catchment with an area of $2415 \mathrm{~km}^{2}$ located in the Northeastern German lowlands. These data sets consist of the STAR-scenario with a time period 1951-2055, the WettReg-scenario covering the period 1961-2100 and the grid based REMO-scenario for the time span 1950-2100. All three data sets are based on the SRES scenario A1B of the IPCC. In our analysis, we compared the meteorological data for the control period obtained from the regional climate change scenarios with corresponding data measured at meteorological stations in the catchment. The results of this analysis indicated, that there are high differences between the different regional climate change scenarios regarding the temporal dynamics and the amount of precipitation. In addition, we applied a water balance model using input data obtained from the different climate change scenarios and analyzed the impact of these different input data on the model output groundwater recharge. The results of our study indicated, that these regional climate change scenarios due to the uncertainties in the projections of precipitation show only a limited suitability for hydrologic impact analysis used for the establishment of future concrete water management procedures in their present state.
\end{abstract}

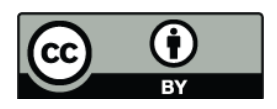

Correspondence to: $\mathrm{M}$. Wegehenkel (mwegehenkel@zalf.de)

\section{Introduction}

Future climate changes may lead to changes of the hydrological conditions of a catchment such as long-term water availability, ground water recharge or drought periods. Therefore, a reliable estimation of the impacts of climate change on catchment hydrology is required to develop adaptation strategies in water resources management. Such studies were carried out in different river basins across Europe using hydrological models and regional climate change scenarios (e.g. Caballero et al., 2007; de Witt et al., 2007; Hattermann et al., 2008). In the last decade, a large amount of such regional climate change scenarios using different global and regional climate models depending on different IPCCSRES-emission scenarios were developed (e.g. Deque et al., 2007). However, the results of different regional climate change scenarios for even one IPCC-SRES scenario such as A1B showed uncertainties depending on the selected regional as well as global climate model (e.g. Deque et al., 2007; Minville et al., 2008). This indicates, that regional climate projections should be evaluated regarding their suitability for hydrological impact analysis (e.g. Bronstert et al., 2007).

The primary goal of our study was a comparison of three different regional climate change projections for the purpose of a model based hydrological impact analysis in a mesoscale catchment located in the Northeastern German lowlands. We applied a water balance model using meteorological input data obtained from these different climate change projections in that catchment and carried out a first preliminary analysis of the impact of these different meteorological input data on some model outputs such as ground water recharge.

Published by Copernicus Publications on behalf of the European Geosciences Union. 


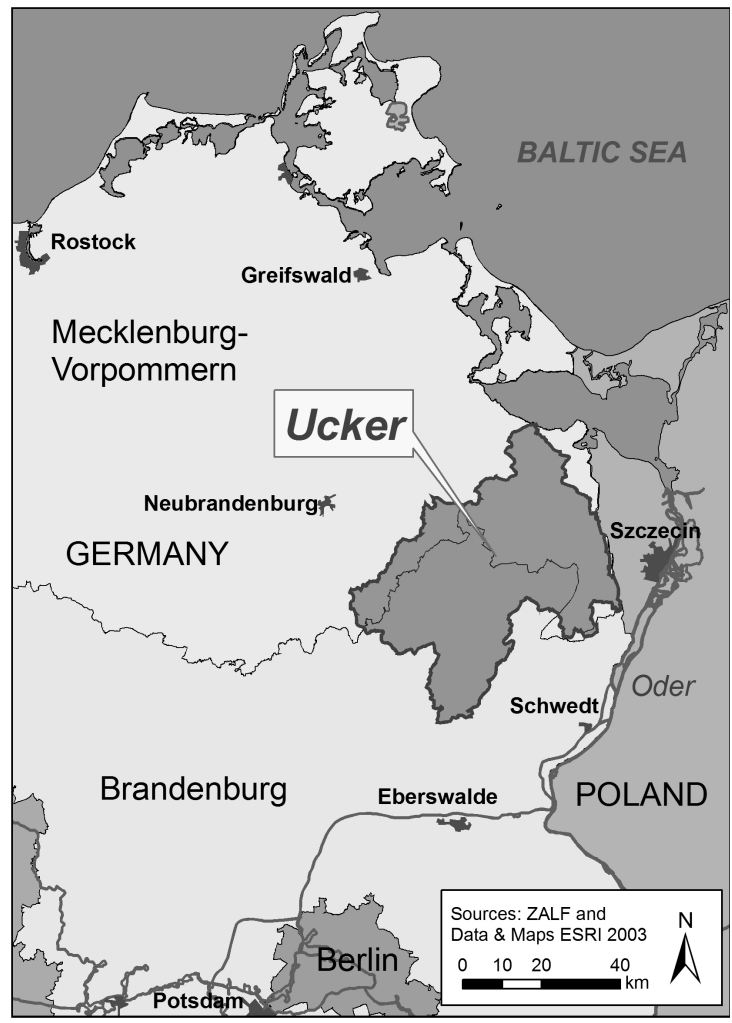

Fig. 1. Location of the Ucker catchment in NE-Germany (from Wegehenkel et al., 2006).

\section{Material and methods}

\subsection{Database}

The location of the Ucker catchment with an area of $2415 \mathrm{~km}^{2}$ is shown in Fig. 1. The actual land cover consists of $5 \%$ settlements, $4 \%$ water bodies, $13 \%$ meadows, $3 \%$ wetlands, $22 \%$ forests, and $53 \%$ arable land. The areas located in the north of the Ucker catchment are covered with sandy soils with low soil water storage capacity. In the southern and western parts, loamy soils with higher soil water storage capacity are located. In the flat river plains, wetlands and peat soils with shallow groundwater tables dominate. The comparison of the actual mean annual rate of precipitation for Germany at $789 \mathrm{~mm} \mathrm{y}^{-1}$ with that for our catchment at about $510 \mathrm{~mm} \mathrm{y}^{-1}$ for the time period 1961-1990 indicates that this catchment is located in one of the driest regions in Germany (Deutscher Wetterdienst, 1999).

In our study, we used three different regional climate change projections, all based on the IPCC-SRES scenario A1B. A detailed description of these scenarios can be obtained from Nakićenović et al. (2000). The first regional scenario is based on the application of the statistical regional downscaling model STAR developed by the Potsdam Institute of Climate Research (Gerstengarbe et al., 2003; Werner and Gerstengarbe, 1997). The STAR-model resamples cli- mate data observed at meteorological stations by cluster analysis using statistics such as seasonality, anomalies, interannual variability and trends of observed air temperatures as an input (Werner and Gerstengarbe, 1997). Projections of future climate conditions are constructed by STAR using the projected trend of future temperatures derived from the model ECHAM4 as main input (Gerstengarbe et al., 2003). The STAR time series 1951-2055 consist of daily rates of precipitation, minimum, maximum, and mean air temperature, water saturation deficit of air, wind speed and global radiation for meteorological stations and are splitted in the reference or control period 1951-2000 and the climate change period 2001-2055 with an increase of $1.4{ }^{\circ} \mathrm{C}$ of the mean annual temperature and a mean decrease of $8 \%$ in the annual precipitation rates (Gerstengarbe et al., 2003). More details about the STAR-model can be obtained from Gerstengarbe et al. (2003) and Werner and Gerstengarbe (1997).

The second climate change projection is the so called WettReg-approach (Wetterlagenbasierte Regionalisierungsmethode $=$ weather-type based regionalization method). WettReg is a combination of a statistical with an analogous down scaling approach and uses statistical relationships between large-scale atmospheric circulation patterns and local climate as well as characteristics of regional climate for different weather types (Enke et al., 2005; Spekat et al., 2007). This approach classifies observed weather types into typical temperature and precipitation regimes for the control period defined from 1961 to 2000. Future climate conditions are derived from corresponding temperature and precipitation regimes obtained from the results of the global climate model ECHAM5/MPI-OM (Jungclaus et al., 2006; Spekat et al., 2007). The time series for meteorological stations according to WettReg consist of meteorological input data with a daily time step similar to the STAR-scenario. In contrast to STAR, WettReg is divided in the reference period 1961-2000 and the climate change period 2001-2100. There exist ten realizations according to ten different weather regimes (Spekat et al., 2007). From these ten realizations, three different precipitation regimes (dry, middle and moist) were evaluated (Spekat et al., 2007). More details about the WettReg-dataset can be obtained from Spekat et al. (2007).

The third climate change projection is based on calculations of the dynamic regional climate model Regional Model (= REMO) of the Max-Planck-Institute for Meteorology, Hamburg, Germany (e.g. Jacob et al., 2007, 2008, second delivery corrected for horizontal shift). The grid based model REMO has a spatial resolution of $0.088^{\circ}$ approx. $10 \times 10 \mathrm{~km}$. Large-scale boundary conditions and forcing inputs are obtained from the global climate model ECHAM5 (Jacob et al., 2007). Similar to WettReg and STAR, we used meteorological data from REMO-Grids with a daily time step, provided by the Max-Planck-Institute for Meteorology, Hamburg, Germany within the research-project NEWALNET (Ende, 2009). 
The other spatial data set for the model simulations consists of a land cover map, a soil map, a river net map and a digital elevation model. More information about the spatial data base can be obtained from e.g. Wegehenkel et al. (2006) and Wegehenkel and Kersebaum (2009).

\subsection{Simulation model}

The hydrological model THESEUS used in our study is coupled to a Geographical Information System and needs three digital maps regarding hydrotopes, subbasins and river net (Wegehenkel et al., 2006). Hydrotopes are the elementary spatial modelling units each with an assumed hydrological uniform behaviour resulting from the overlay of the land cover map, the soil and subbasins map as well as the digital elevation model. Therefore, the database of each hydrotope consists of information about soil type, groundwater table, land cover, corresponding subbasin and mean elevation. The river net map contains information about the cross profiles of the river sections, elevation of the river nodes and reference to the corresponding downstream river section.

For each hydrotope in the catchment, water balance is calculated based on daily time steps. Snowmelt is simulated by a degree-day approach. Potential reference evapotranspiration (PET) is calculated as a function of global radiation, saturation deficit of air and wind speed according to Wendling et al. (1991). The partitioning of PET in transpiration, interception and evaporation is simulated using simple vegetation type specific seasonal time courses for rooting depth, plant height and soil cover. Interception is calculated by a modified linear storage approach. Actual evapotranspiration is determined by PET, soil cover and by a root density function, which establishes water extraction by evapotranspiration from soil layers.

Infiltration into the topsoil layer and runoff generation is calculated by a modified approach according to Holtan (1961). Actual water content and water fluxes of each soil layer are calculated using a capacity approach with nonlinear storage routing according to Glugla (1969). The water flux across the lower boundary of the soil profile is defined as groundwater recharge. In the presence of groundwater in the soil profile, capillary rise is calculated depending on soil texture, bulk density, and distance from the soil layer to groundwater table and soil water content in the layer using tabular data published in AG Boden (2005).

For each modelling time step, surface runoff is routed by a fast linear storage and groundwater recharge is routed by a slow linear storage for base flow for each subbasin. Due to the low amount of steep slopes in the catchment, interflow is neglected. The discharge of each subbasin comprised of the outflows of these two storages is assigned to the corresponding river section of the subbasin. The stream flow through the river net is simulated by a linear storage cascade of all river sections down
Table 1. Types of weather stations in the Ucker catchment.

\begin{tabular}{lcccc}
\hline No & Name & Type_Wettreg & Type_STAR & Type_DWD_MD \\
\hline 1 & Ahlbeck & Precipitation & - & Precipitation \\
2 & Altentreptow & Precipitation & - & Climate \\
3 & Angermuende & Climate & Climate & Climate \\
4 & Bredereiche & Precipitation & - & Precipitation \\
5 & Carpin-Serran & Precipitation & Climate & Climate \\
6 & Friedrichswalde & Precipitation & Climate & Climate \\
7 & Fuerstenberg & Precipitation & - & Precipitation \\
8 & Goeritz & Precipitation & Climate & Precipitation \\
9 & Grambow & Precipitation & Climate & Precipitation \\
10 & Neuglobsow & Climate & Climate & Precipitation \\
11 & Penkun & Precipitation & Climate & Climate \\
12 & Penzlin & Precipitation & Climate & Precipitation \\
13 & Prenzlau & Precipitation & Climate & Precipitation \\
14 & Ratheburg & Precipitation & - & Precipitation \\
15 & Uckermuende & Climate & Climate & Climate \\
\hline
\end{tabular}

to the catchment outlet. A more detailed description of the database and the model can be obtained from e.g. Wegehenkel et al. (2006).

\subsection{Analysis and evaluation of regional climate change projections}

In addition to the STAR- (=STAR) and REMO-scenario (=REMO), we selected the data sets with the predefined dry (=WR_dry) and the middle precipitation regime (=WR_middle) from the WettReg-data set. Due to the different time periods of the scenarios, we defined a common control period 1961-2000 for all climate change projections for an evaluation of the presentation of the current climate conditions by STAR, REMO and WettReg. Weather stations are usually classified as climate stations measuring e.g. precipitation, global radiation, wind speed and air humidity or as precipitation stations observing only rainfall. A comparison of the classification of the 15 weather stations for the Ucker catchment used in the climate change projections WettReg and STAR with that obtained from the German Weather Service (=DWD) showed some discrepancies (Table 1). In contrast to the classification obtained from DWD, the STARscenario defined all stations as climate stations (Table 1). The WettReg-scenario classified only three climate stations in contrast to six climate stations according to DWD (Table 1). Only two stations, Angermuende and Uckermuende, were defined identically as climate stations by DWD, STAR and WettReg (Table 1). This low amount of identical climate stations hampers a sufficient comparison of e.g. temperature or air humidity measured at the weather stations with corresponding ones obtained from the STAR- and WettRegdataset. Therefore, we focused in our evaluation of the climate change scenarios only on precipitation. This evaluation consists of the comparison of precipitation rates obtained from the climate change projections with corresponding ones measured at 15 meteorological stations located inside and outside of the catchment (Fig. 2). The precipitation 


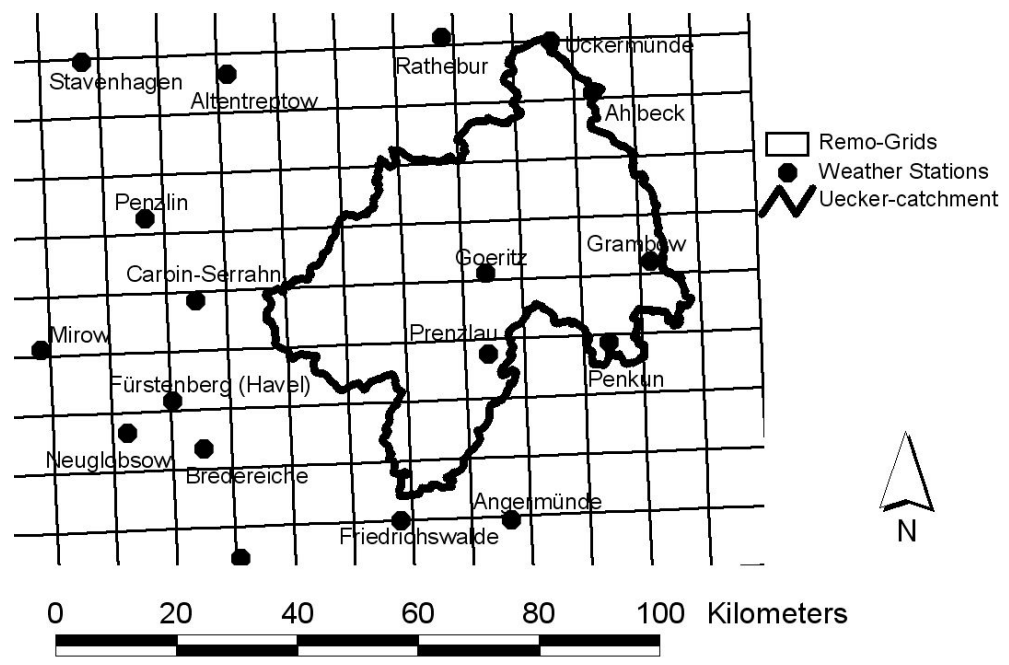

Fig. 2. Station network for STAR and WettReg as well as REMO-Grids for the Ucker catchment.

rates obtained from the stations and from the scenarios were used without any additional modification. In the case of the grid based REMO-data set, we simply compared the precipitation rates measured at the station with the corresponding mean rates calculated from rainfall rates obtained from the grid with the station located inside and the eight surrounding REMO-grids (Fig. 2). This procedure is recommended by the providers of the REMO-data set (UBA-MPI, 2008). For the analysis, we compared cumulative times series, cumulative frequency distributions, differences in annual rates and spatial rainfall distributions obtained from the different regional climate data sets.

\subsection{Model set up}

The spatial distribution of meteorological input data for the modelling units hydrotopes was interpolated from stations for STAR and WettReg using an inverse-distance procedure included in the model. For the REMO-data, we simply used the time series of the corresponding grid with the station located inside and treated these grid-based time series similar like station data with the same interpolation method as STAR and WettReg (Fig. 2).

For forested areas, we assumed the existence of adult forest stands for the total simulation period. Initial soil water contents for the simulation runs were set equal to field capacity. In a former study, the model was calibrated using measured discharge rates and observed meteorological input data from the period 1989-2003. Within this calibration, only two model parameters, which influences the determination of runoff and baseflow and, therefore, mainly impacts channel discharge, were modified to match the measured discharge rates with an acceptable precision (Wegehenkel et al., 2006; Wegehenkel and Kersebaum, 2009). The other data such as soil hydraulic properties were not changed.
In the recent study, this so calibrated model was applied using the meteorological data provided by the climate change projections without any further correction. The model simulation was carried out continuously for 90 years ranging from 1 January 1961 to 31 December 2050 with a daily time step. Due to the different time spans of the climate change periods such as 2001-2055 for STAR and 2001-2100 for WettReg and REMO, we defined the climate change period for the analysis of the model outputs 2011-2050 with a duration of 40 years. This equals the duration of the control period 1961-2000 and enables the direct comparison of cumulative frequency curves and cumulative rainfall.

\section{Results and discussion}

\subsection{Comparison of climate scenarios with station data}

The comparison of cumulative daily rainfall obtained from DWD-station data with those according to the STAR-, WettReg- and REMO-scenario for the common control period 1961-2000 indicated an overestimation of rainfall by the REMO-approach in contrast with the other data sets. A comparison of measured cumulative daily rainfall from six selected stations with corresponding scenario data is presented in Fig. 3. In comparison with the station data, REMO overestimates cumulative daily rainfall in an order of magnitude of $16-41 \%$ of cumulative station rainfall (Fig. 3). Only in case of the station Altentreptow, located Northeast outside of the catchment (Fig. 2), cumulative rainfall obtained from all climate change scenarios were higher than cumulative rainfall according to the station data (Fig. 3). For the other stations such as Angermuende, Friedrichswalde, Penkun or Uckermuende, cumulative daily rainfall obtained from the WettReg_dry-scenario is mainly higher than those obtained from WettReg_middle, STAR and station data. Wettreg_dry overestimates cumulative rainfall in an order of magnitude 


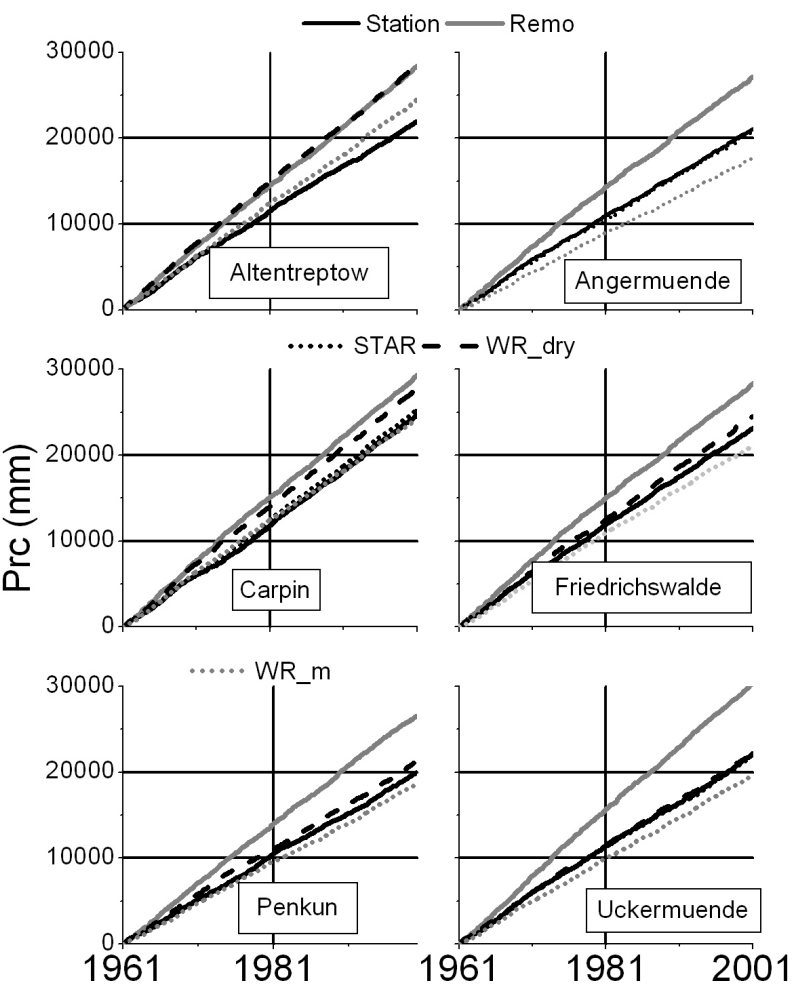

Fig. 3. Comparison of cumulative daily rainfall $(=\operatorname{Prc})$ in $\mathrm{mm}$ for six selected stations obtained from weather station (= station) and the climate change scenarios REMO (= REMO), STAR (= STAR), WettReg_dry (=WR_dry) and WettReg_middle (= WR_m) for the control period 1961-2000.

up to $12 \%$ of that calculated from the station data. In contrast, cumulative rainfall obtained from the WettReg_middlescenario is lower than those obtained from STAR, WettReg_dry and station data. This underestimation of cumulative rainfall by WettReg_middle is an order of magnitude of up to $16 \%$ of the station data (Fig. 3). Please note that we used the original denomination of the WettReg-dataset although our results might indicate a contradiction between WettReg_dry with more rainfall and WettReg_middle with a lower amount of precipitation. However, for all stations in the Ucker catchment, cumulative daily rainfall data obtained from the STAR-scenario showed the best fit to the station data with differences $<2 \%$ of cumulative station rainfall (Fig. 3).

The comparison of cumulative frequency graphs of daily station rainfall with corresponding ones obtained from the climate change scenarios indicated also differences between the REMO-scenario and the station data as well as the other climate change scenarios especially regarding maximum and the amount days without rainfall (Fig. 4). In contrast to REMO-, WettReg- and STAR-scenario were mainly similar with the station data (Fig. 4). However, similar to cumulative daily rainfall, the STAR-scenario showed the best fit to the station data.

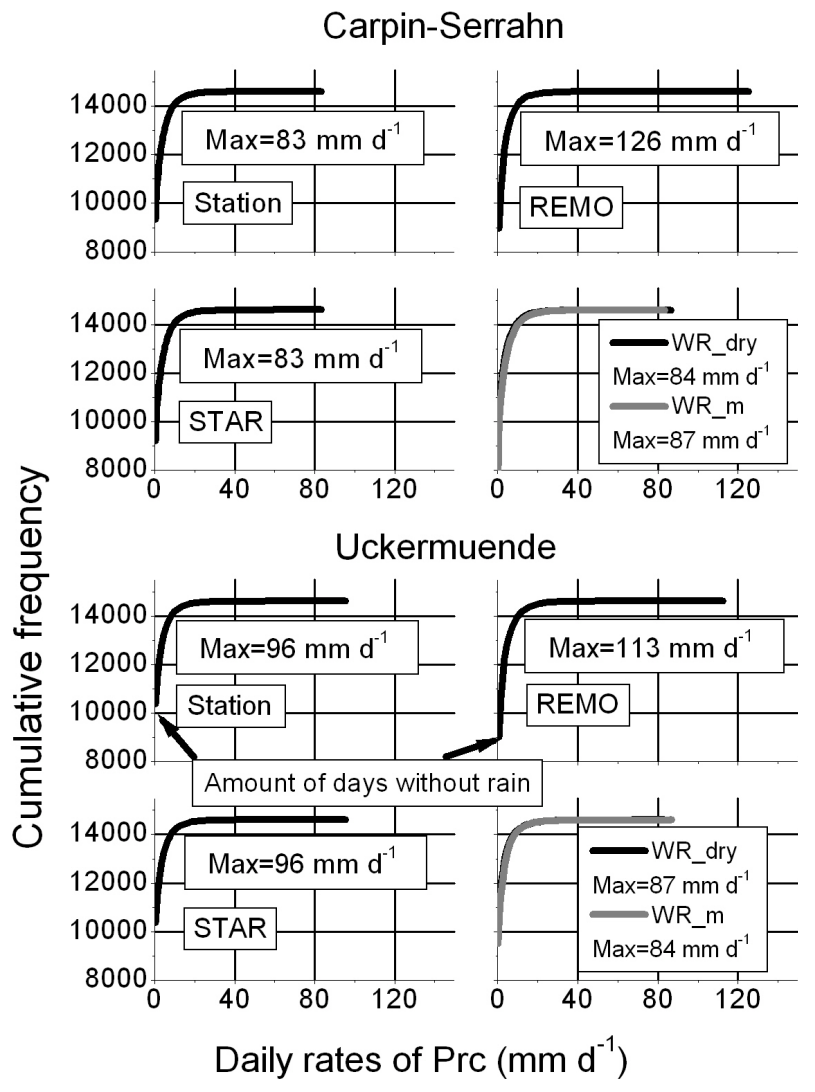

Fig. 4. Cumulative frequency curve and maximum (= Max) of daily precipitation rates $(=\mathrm{Prc})$ of the control period 1961-2000 measured at the weather stations Ueckermünde and Carpin-Serrahn in comprison with corresponding curves obtained from the climate change scenarios REMO, STAR, Wettreg_dry (=Wr_dry) and WettReg_middle (=WR_m).

These findings were also indicated by the differences between annual rates of precipitation measured at the stations and corresponding annual rates obtained from the climate change scenarios for the control period 1961-2000 (Fig. 5). In comparison with the station data, the REMO scenario showed mainly an overestimation of annual rates up to $611 \mathrm{~mm} \mathrm{y}^{-1}$ corresponding to $162 \%$ of the station data (annual rate station minus annual rate REMO means negative data in Fig. 5). Especially in the year 1982, measured annual rainfall rates ranged within $308-551 \mathrm{~mm} \mathrm{y}^{-1}$ in contrast to REMO with annual rates of precipitation within 723-1004 $\mathrm{mm} \mathrm{y}^{-1}$. Annual rainfall rates obtained from WettReg_dry and WettReg_middle showed over- and underestimation in an order of magnitude of $0-528 \mathrm{~mm} \mathrm{y}^{-1}$ corresponding to $0-136 \%$ of the station data (Fig. 5). Mainly only minor differences between annual rates obtained from the STAR-Scenario and those obtained from the stations could be observed (Fig. 5). However, these observed differences in our study should not be used as an indicator of the quality of the climate projections and, therefore, should be interpreted more as an additional measure of the uncertainties 

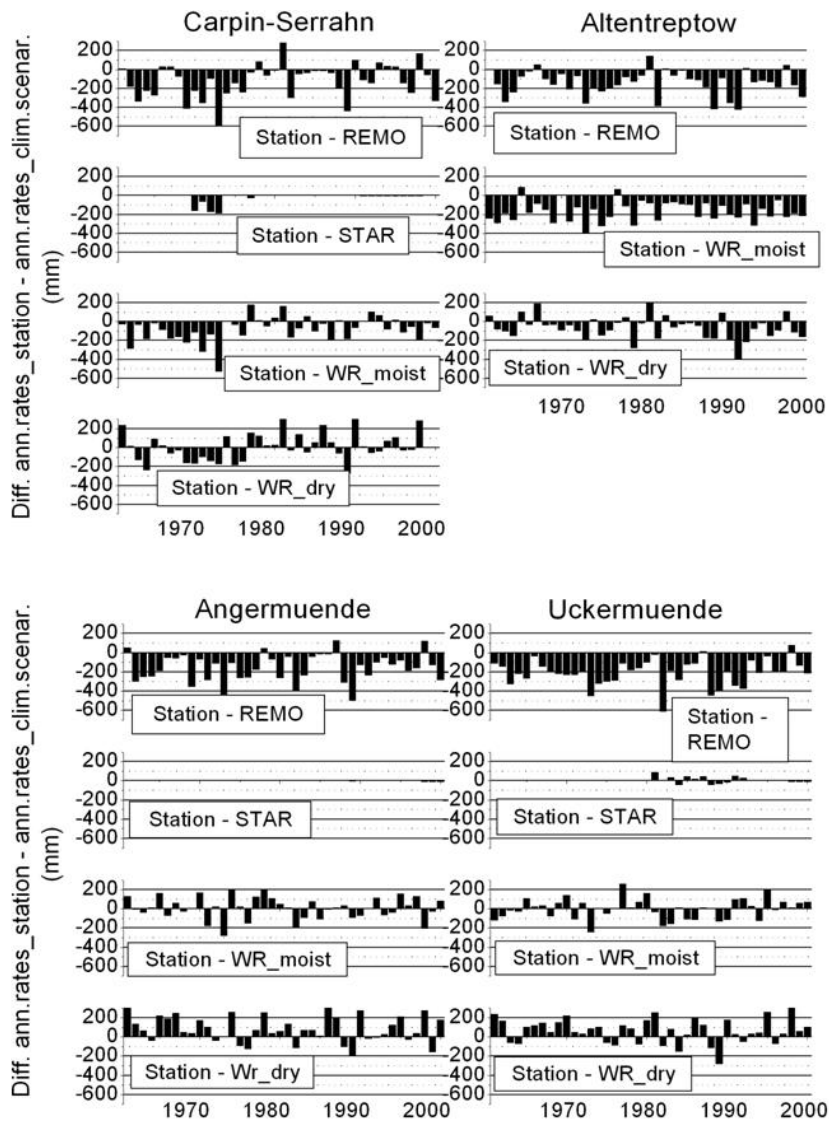

Fig. 5. Differences between annual rates of precipitation measured at the weather stations Carpin-Serrahn, Altentreptow, Angermuende and Uckermuende and corresponding rates obained from the climate change scenarions REMO (=Station - REMO), STAR (= Station - STAR), WettReg_dry (=Station - WR_dry) and WettReg_middle (=Station - WR_m) for the control period 1961-2000.

of precipitation rates simulated by different climate change projections. The good fit of the STAR-model to the station data might be mainly due to the use of observed data for the generation of the times series for the control period (Gerstengarbe et al., 2003). In contrast, REMO uses outputs of the global climate model ECHAM5 for the generation of the time series (Jacob et al., 2007, 2008). Furthermore, this good fit does not mean, that the future climate projection obtained from the STAR-method is the most reliable scenario for the application for hydrologic impact analysis. In a paper published by Bronstert et al. (2007), STAR, WettReg and REMO were also evaluated for their suitability for hydrological impact studies comparing simulated and observed precipitations for the control period in a region located in South Germany covering the federal states of Bavaria and Baden-Wuerttemberg with a total area of $106000 \mathrm{~km}^{2}$. In that study, the WettReg-method showed differences between observed and simulated precipitation of about $20 \mathrm{~mm} \mathrm{y}^{-1}$, which corresponds to $2 \%$ of the observed rainfall. How-

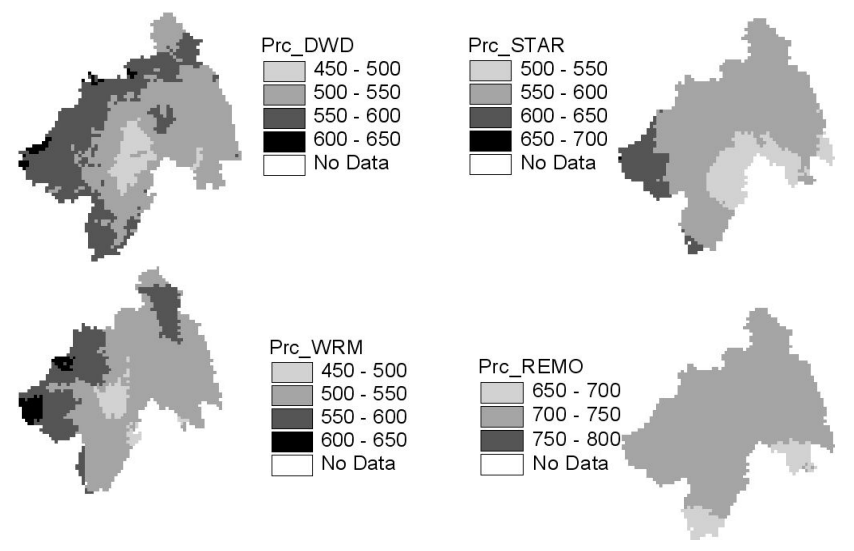

Fig. 6. Spatial distribution of mean annual rates of precipitation in $\mathrm{mm} \mathrm{y}^{-1}$ obtained from German Weather Service (= Prc_DWD) and calculated from climate change scenarios STAR (= Prc_STAR), Wettreg_middle (=Prc_WRM) and REMO (= Prc_REMO), all based on the time period 1961-1990.

ever, the REMO-scenario showed differences of more than $400 \mathrm{~mm} \mathrm{y}^{-1}$, which was approx. $45 \%$ of observed precipitation (Bronstert et al., 2007).

A comparison of the spatial distribution of mean annual precipitation rates for the period 1961-1990 obtained from DWD (DWD, 1999) with those interpolated from the different climate change scenarios indicated further the overestimation of annual rates of precipitation by the REMOScenario in comparison with the station data and the other climate change scenarios STAR and WettReg (Fig. 6). In our study, the spatial distribution of precipitation obtained from the climate change projections was calculated using a simple inverse-distance procedure. In contrast, DWD used a much more sophisticated multistep procedure based mainly on regression between precipitation and topography (MüllerWestermeier, 1995). This discrepancy between both interpolation procedures might have an additional impact on the differences between the spatial precipitation patterns according to DWD (1999) and those according to the climate scenarios.

Despite the fact, that climate change scenarios such as WettReg and REMO does not simulate real rainfall series, our comparison allows a general estimation of over- or underestimation trends of climate change scenarios in comparison with station data and of the uncertainties of climate change scenarios regarding the outputs for precipitation.

\subsection{Preliminary results of the application of the water balance model}

In a former study, we applied the water balance model in the Ucker catchment using the STAR-scenario and compared the model results for the control period 1951-2000 with those obtained from the climate change period 2001-2050. The comparison indicated a reduction of precipitation in the climate change period 2001-2050 in an order of magnitude of 


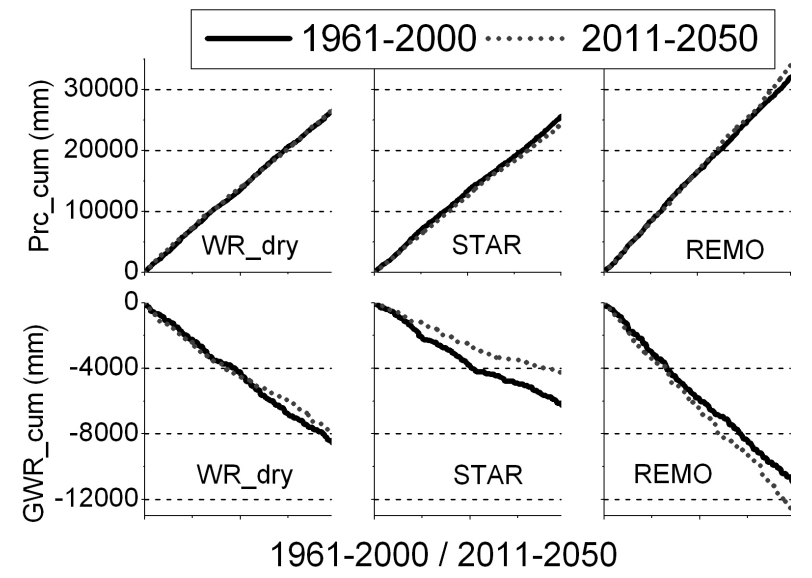

Fig. 7. Comparison of cumulative rates of daily precipitation (= Prc_cum) and simulated groundwater recharge (=GWR_cum) for the control period 1961-2000 and the defined climate change period 2011-2050 at the selected hydrotope with arable land/sandy soil, simulated using the climate change scenarios WettReg_dry (=WR_dry), STAR and REMO.

2-10\% of the control period 1951-2000 and a decrease of groundwater recharge in an order of magnitude of 1-94\% for the climate change period 2001-2050 (Wegehenkel and Kersebaum, 2009).

In the recent study, we carried out a first application of the water balance model using the scenarios WettReg_dry, STAR and REMO and comparing some preliminary model results for the new defined control period 1961-2000 with those for the new defined climate change period 2011-2050. The scenario WettReg_dry indicated a reduction of precipitation in the climate change period $2011-2050$ by up to $3 \%$ of the control period 1961-2000. However, the REMO-scenario showed an increase of precipitation in the climate change period 2011-2050 in order of 1-12\% of the control period 1961-2000 leading to a simulated mean relative increase of groundwater recharge of $19 \%$ for the Ucker catchment. An example of the impact of the different climate change scenarios is presented in Figs. 7 and 8. For a first preliminary analysis, we randomly selected a hydrotope with arable land located on a poor soil with sand contents above $90 \%$ and a field capacity of $11 \mathrm{Vol} \%$ and a hydrotope with coniferous forests located at the same soil. A comparison of cumulative daily rainfall and simulated groundwater recharge for both hydrotopes in the Ucker catchment illustrated that the use of WettReg_dry and STAR led to a reduction of simulated groundwater recharge in the climate change period 20112050 in an order of magnitude of $7-30 \%$ of the control period (Figs. 7 and 8). Due to the increase of precipitation, the results obtained from the model application using the REMO-scenario indicated an increase of simulated groundwater recharge within 1690-1780 mm on both hydrotopes in the climate change period in comparison with the control period 1961-2000 (Figs. 7 and 8). This increase corresponds to $16-20 \%$ of the control period.

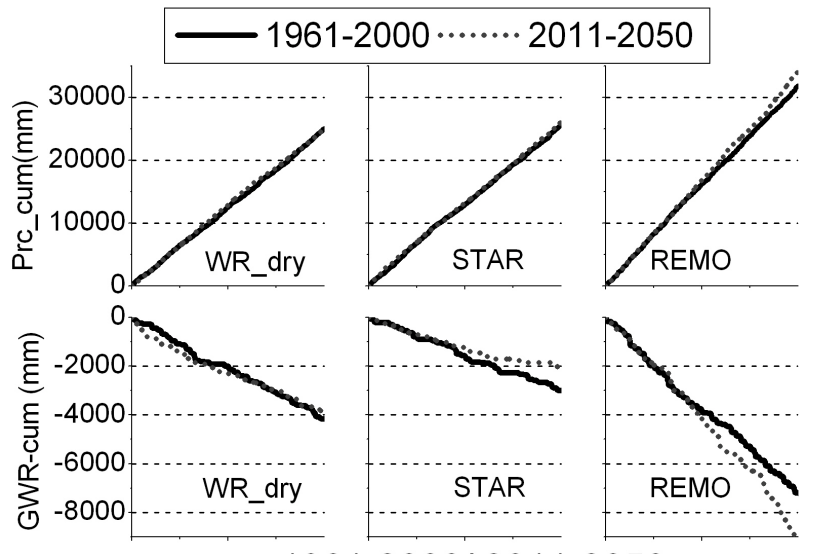

$1961-2000 / 2011-2050$

Fig. 8. Comparison of cumulative rates of daily precipitation (=Prc_cum) and simulated groundwater recharge (=GWR_cum) for the control period 1961-2000 and the defined climate change period 2011-2050 at the selected hydrotope with coniferous forest/sandy soil, simulated using the climate change scenarios WettReg_dry (=WR_dry), STAR and REMO.

\section{Conclusions}

Due to these uncertainties at the present state of the climate projections, the results of our study are preliminary and a definition of some confidence intervals is difficult. However, such a definition of confidence intervals is essential for the acceptance of the results of such impact studies by local stakeholders regarding adaptation strategies in water resources management. Taking into account our results from the evaluation of the three different regional climate change scenarios, there are large differences between the climate change scenarios regarding the temporal dynamics and the amount of precipitation. These differences led to contradictory modelling results regarding groundwater recharge especially between the model outputs based on the use of the REMO-scenario and those based on the STAR- and the WettReg_dry-scenario. However, there are some limitations in our analysis such as no Bias-correction of REMO data and the limited compatibility between meteorological time series obtained from grids and station based time series. However, despite these limitations, these uncertainties hamper, e.g. the recommendation of concrete water resource management options based on hydrological impact analysis using model outputs calculated with input data obtained from regional climate change projections in their present state.

Acknowledgements. The work was founded from the Germany Federal Ministry of Consumer Protection, Food and Agriculture and the Ministry of Agriculture, Environmental Protection and Landscape Planning, Brandenburg. We have to thank Germany's Meteorological Service and F. W. Gerstengarbe from the Potsdam Institute of Climate Impact Research for providing meteorological data and the STAR-Scenario. The WettReg-data set was provided by CEC Potsdam and the REMO-data set was provided by the 
Max-Planck-Institute of Meteorology (MPI-M) Hamburg, both in cooperation with the Federal Environment Agency (UBA) Dessau within the project Newal-Net founded by the Federal Ministry of Education and Research under the Contract-No. 0330562A. The digital elevation model DEM25 was provided by the Federal Agencies Landesvermessungsamt Brandenburg and Landesvermessungsamt Mecklenburg-Vorpommern (LvermA $B B+M V, G B-A$ 03/1).

Edited by: A. Wahren, F. Tavares Wahren, and K.-H. Feger

Reviewed by: two anonymous referees

\section{References}

AG Boden: Bodenkundliche Kartieranleitung, Bundesanstalt für Geowissenschaften und Rohstoffe und den Geologischen Landesämtern in der Bundesrepublik Deutschland, Hannover, 5. Aufl, 438 pp., 2005 (in German).

Bronstert, A., Kolokotronis, V., Schwandt, D., and Straub, H.: Comparison and evaluation of regional climate impact analysis: General scheme and application example, Int. J. Climatol., 27, 1579-1594, 2007.

Caballero, Y., Voirin-Morel, S., Habets, F., Noilhan, J., LeMoigne, P., Lehenaff, A., and Boone, A.: Hydrological sensitivity of the Adour-Garonne river basin to climate change, Water Resour. Res., 43, W07448. doi:10.1029/2005WR004192, 2007.

Deutscher Wetterdienst: Digitaler Klimaatlas Bundesrepublik Deutschland Teil 1 Lufttemperatur, Niederschlagshöhe, Sonnenscheindauer, Offenbach am Main, 1999 (in German).

Deque, M., Rowel, D. P., Lüthi, D., Giorgi, F., Christensen, J. H., Rockel, B., Jacob, D., Kjellström, E., de Castro, M., and van den Hurh, B.: An intercomparison of regional climate simulations for Europe: assessing uncertainties in model projections, Climatic Change, 81, 53-70, 2007.

De Witt, M. J. M., Van den Hurk, B., Warmerdam, P. M. M., Torfs, P. J. J. F., Roulin, E., and van Deursen, W. P. A.: Impact of climate change on low-flows in the river Meuse, Climatic Change, 82, 351-372, 2007.

Ende, H. P.: Klimaplastische Wälder für Regionen mit Zukunft der Forschungsverbund NEWAL-NET, Forst und Holz, 64(10), 11-13, 2009 (in German).

Enke, W., Deutschländer, T., Schneider, F., and Küchler, W.: Results of five regional climate studies applying a weather pattern based downscaling method to ECHAM4 climate simulation, Meteorol. Z., 14, 247-257, 2005.

Gerstengarbe, F. W., Badeck, F., Hattermann, F., Krysanova, V., Lahmer, W., Lasch, P., Stock, M., Suckow, F., Wechsung, F., and Werner P. C.: Studie zur klimatischen Entwicklung im Land Brandenburg bis 2055 und deren Auswirkungen auf den Wasserhaushalt, die Forst- und Landwirtschaft sowie die Ableitung erster Perspektiven, Potsdam, PIK-Report No. 83, 96 pp., 2003 (in German).

Glugla, G.: Berechnungsverfahren zur Ermittlung des aktuellen Wassergehaltes und des Gravitationsabflusses, Albrecht-ThaerArchiv, 13, 371-376, 1969 (in German).

Hattermann, F., Post, J., Krysanova, V., Conradt, T., and Wechsung, F.: Assessment of Water Availability in a Central-European River Basin (Elbe) under Climate Change, Adv. Clim. Change Res. Suppl., 4, 42-50, 2008.
Holtan, H. N.: A concept for infiltration estimates in watershed engineering, US Dept. ARS, Washington D.C., 41-51, 1961.

Jacob, D. L., Bärring, O. B., Christensen, J. H. , Christensen, S., Hagemann, S., Hirschi, M., Kjellström, E., Lenderink, B., Rockle, C., Schär, S. I., Seneviratne, S., Somot, A., van Ulden, A., and van den Hurk, B.: An intercomparison of regional climate models for Europe: Design of the Experiments and model performance, PRUDENCE, Special Issue, Climatic Change, Vol. 81, Supplement 1, 2007.

Jacob, D., Göttel, H., Kotlarski, S., Lorenz, P., and Sieck, K.: Klimaauswirkungen und Anpassungen in Deutschland- Phase 1: Erstellung regionale Klimaszenarien für Deutschland, Techn. Report UBA, 154 pp., 2008 (in German).

Jungclaus, J. H., Botzet, M., Haak, H., Keenlyside, N., Luo, J. J., Latif, M., Marotzke, J., Mikolajewicz, U., and Roeckner, E.: Ocean circulation and tropical variability in the coupled model ECHAM5/MPI-OM, J. Climate, 19, 3952-3972, 2006.

Minville, M., Brisette, F., and Leconte, R.: Uncertainty of the impact of climate change on the hydrology of a nordic watershed, J. Hydrol., 358, 70-83, 2008.

Müller-Westermaier, G.: Numerisches Verfahren zur Erstellung klimatologischer Karten, Berichte des Deutschen Wetterdienstes, Nr. 193, Offenbach, 1995 (in German).

Nakićenović, N., Alcamo, J., Davis, G., DeVries, B., Fenhann, J., Gaffin, S., Gregory, K., Gruebler, A., Jung, T. Y., Kram, T., La Rovere, E. L., Michaelis, L., Mori, S., Morita, T. Pepper, W. Pitcher, H., Price, L., Riahi, K., Roehrl, A., Rogner, H. H., Sankovski, A., Schlesinger, M., Shukla, P., Smith, S., Swart, R., VanRooijen, S., Victor, N., and Dadi, Z.: Special Report on Emissions Scenarios: A Special Report of Working Group III of the Intergovernmental Panel on Climate Change, Cambridge University Press, Cambridge, 600 pp., 2000.

Spekat, A., Enke, W., and Kreienkamp, F.: Neuentwicklung von regional aufgelösten Wetterlagen für Deutschland und Bereitstellung regionaler Klimaszenarios auf der Basis von globalen Klimasimulationen mit den Regionalisierungsmodell WETTREG auf Basis von globalen Klimasimulationen mit ECHAM5/MPIOM T63L31 2010 bis 2100 für die SRES-Szenarios B1, A1B, und A2, Techn. Report UBA, 149 pp., 2007 (in German).

UBA-MPI: Hinweise für REMO-Datennutzer, available at http://www.mpimet.mpg.de/file-admin/staff/pfeifersusanne/ REMO $\backslash$ UBA/REMO-UBA-Hinweise.pdf (last access: 20 December 2009), 2008.

Wegehenkel, M., Heinrich, U., Uhlemann, S., Dunger, V., and Matschullat, J.: The impact of different spatial land cover data sets on the outputs of a hydrological model: a modelling exercise in the Ucker catchment, North-East Germany, Phys. Chem. Earth, 31, 1075-108, 2006.

Wegehenkel, M. and Kersebaum, K. C.: An assessment of the impact of climate change on evapotranspiration, groundwater recharge and low flow conditions in a mesoscale catchment in Northeast Germany, J. Plant Nutr. Soil Sci., 172, 737-744, 2009.

Werner, P. C. and Gerstengarbe, F. W.: Proposal for the development of climate scenarios, Clim. Res., 8, 171-182, 1997.

Wendling, U. H., Schellin, G., and Thomä, M.: Bereitstellung von täglichen Informationen zum Wasserhaushalt des Bodens für die Zwecke der agrarmeteorologischen Beratung, Z. Metereol., 41(6), 1-16, 1991. 